\title{
Influence of wrapping and storage conditions on the shelf life and chemical fruit quality of mango
}

\author{
M.R. Khan ${ }^{1 *}$ and R. Alam ${ }^{1}$ \\ 1 EXIM Bank Agricultural University Bangladesh, Bangladesh \\ *Corresponding author email: mujiburkhan.bd@gmsil.com
}

\begin{abstract}
The intention of this post-harvest analysis was to see how the interaction of wrapping materials and storage requirements influenced the shelf life and chemical fruit quality of the 'Khirsapat' mango. 'Khirsapat' mangoes were harvested when they were fully mature and wrapped in various materials, viz. Low-density polyethylene (LDPE) + No perforation, LDPE + $5 \%$ perforation, LDPE + Blotting paper inside, LDPE $+5 \%$ perforation+ Blotting paper inside, Corrugated Fiber Board (CFB) Box (5\% ventilation), LDPE (5\% perforation) + CFB Box (5\% ventilation), Plastic crate \& Control (without any wrapping). Biochemical parameters such as TSS, titratable acidity, reducing sugars, and total sugars were measured in the fruits. According to the data, the physicochemical characteristics of a 'Khirsapat' mango were significantly impacted by the wrapping materials and storage period. Wrapping of 'Khirsapat' mango in LDPE 5\% perforation + CFB Box 5\% ventilation at temperature $12 \pm 1^{\circ} \mathrm{C}$ has shown that, up to the $12^{\text {th }}$ day the most successful treatment approach showed a more progressive increase in TSS and total sugar than other treatments. The cultivar's optimum shelf life and nutritional value retention was found by this study. However, in terms of sensory quality, the highest score for 'Khirsapat' mango was achieved in a CFB Box with $5 \%$ ventilation.
\end{abstract}

Keywords: CFB box, cold storage, LDPE, post-harvest, reducing sugar, wrapping materials.

\section{INTRODUCTION}

Mango (Mangifera indica L.) which is considered as "King of Fruits" is a popular commercial fruit in the tropics. It is used to produce processed items such as sweets, leather, relishes, pickles, juices, and many others, in addition to fresh use. Mango production in Bangladesh is estimated to be around 12,88,000 tons (BBS, 2019). Mango production accounted for $1,03,00$ acres or 25.22 percent of total fruit production. During the 2018-2019 growing season, the average yield was $92 \mathrm{~kg} /$ acre (BBS, 2019). Mangoes come in a huge range of cultivated cultivars and hybrids. 'Khirasapat', also known as 'Himsagar', is a delicious and early cultivar among them. It fully matures in May and is available from the first week of May to the end of June in the market. The 'Khirsapati' mango from Chapainawabganj recently received the Geographical Indication (GI) label. The fruit is ovate to ovate-oblique in shape and medium in size. With a medium-thick peel, the pulp is firm, cadmium yellow in color, and fiber less. The flavor is delightful, with a trace of turpentine, and the tastes sweet with plenty of juice (Srivastava, 1998). However, due to the early senescent feature, it can't be stored for a long period of time. With a maximum storage time of five to seven days, the fruit generates blackish spots and spoils quickly. It is most certainly incapable of tolerating even the most minor transportation risks (Siddiqui and Dhua, 2009). 
To resolve these obstacles, appropriate post-harvest techniques to improve the storage quality of mango fruits are needed. Temperature control during storage and handling delays ripening and retains fresh-market quality (Johnson et al., 1998) because physicochemical changes in the fruit are significantly reduced at these temperatures. Mango fruit consistency is also affected by wrapping materials and ripening techniques (Malik et al., 2008).

\section{MATERIALS AND METHODS}

This study aims to find out the impact of wrapping materials and storage environment on various physiochemical properties of 'Khirsapat' mango at the Horticulture Laboratory of EXIM Bank Agricultural University Bangladesh (EBAUB). 'Khirsapat' mangoes were collected from various mango orchards and local fruit markets in the Chapainawabganj district at a fully mature but unripe level. Fruits were picked from the trees in the morning. The fruit stalks were cut up to a size of about $1 \mathrm{~cm}$ with secateurs and washed in tap water before being purified with $50 \mathrm{ppm}$ chlorine. The fruits were then dried on the surface with a fan. The mangoes were then packed in LDPE, plastic crates, CFB box, and LDPE+ CFB box and kept in cold storage at $12 \pm 1^{\circ} \mathrm{C}$ and $85-95 \%$ relative humidity (RH). After a three- day delay, readings were taken again. The experiment was performed in complete randomized design with three replications. Treatment details are given in Table 1.

\section{Chemical analysis}

The mango samples were examined for a cultivar of compounds. The TSS was calculated using a refractometer $\left(0-32^{\circ}\right.$ B). The A.O.A.C. (1990) approach was used to assess titratable acidity. The Lane and Eynon approach were applied to calculate reducing and total sugars.

\section{Sensory evaluation}

For sensory evaluation, Ranganna (1991) proposed 1-9 Hedonic scale was applied.

Table 1. Treatment details used for wrapping of mango

\begin{tabular}{|c|c|}
\hline $\mathrm{T}_{1}$ & Low-density polyethylene (LDPE) + No perforation \\
\hline $\mathrm{T}_{2}$ & LDPE + 5 \% perforation \\
\hline $\mathrm{T}_{3}$ & LDPE + Blotting paper inside \\
\hline $\mathrm{T}_{4}$ & LDPE + 5\% perforation+ Blotting paper inside \\
\hline $\mathrm{T}_{5}$ & Corrugated Fiber Board (CFB) Box (5\% ventilation) \\
\hline $\mathrm{T}_{6}$ & LDPE (5\% perforation) + CFB Box (5\% ventilation) \\
\hline $\mathrm{T}_{7}$ & Plastic crate \\
\hline $\mathrm{T}_{8}$ & Control (without any wrapping) \\
\hline
\end{tabular}

\section{RESULTS AND DISCUSSIONS}

The investigation's findings are summarized and discussed in this section under the headings below.

\section{TSS ( $\left.{ }^{0} \mathrm{Brix}\right)$}

Wrapping and storage of fresh 'Khirsapat' mango had a significant impact on the chemical constituents studied in this research. The TSS content of mango fruits gradually enhanced during storage. The rise in TSS content during storage may be attributed to water losses from respiration and evaporation, as well as juice concentration (Wills et al., 1980). 
Cua (1989) also attributed the rise to the hydrolysis of the polysaccharide, which converts starch to sugar. For the cultivar, the highest TSS was found in $\mathrm{T}_{6}$ (LDPE $5 \%$ perforation + CFB Box 5\% ventilation) (Figure 1).

It's possible that the film wrapping with CFB box and lower storage temperature improved TSS maintenance since aging was minimized by reduced respiration rate and other undesirable metabolic modifications (Pongener et al., 2011).

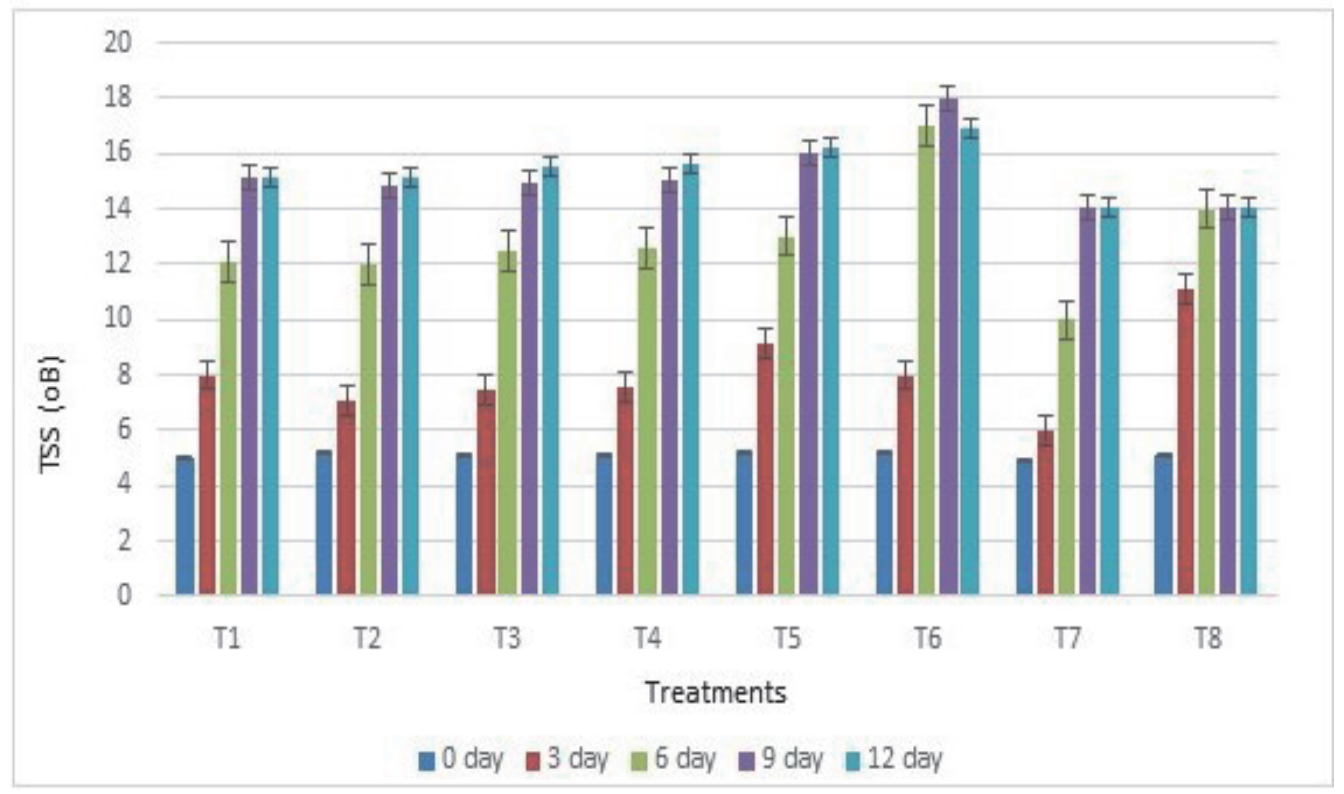

Figure 1. Effect of wrapping materials and storage on TSS ( $\left.{ }^{\circ} \mathrm{B}\right)$

\section{Reducing sugars (\%)}

The reducing sugars of mango fruits treated with different treatments followed a similar pattern to the TSS content (Figure 2). The initial rise in reducing sugars of fruits in various packages may be due to water loss from the fruits and sugar conversion from polysaccharides and pectic substances. The increase in reducing sugars over a 12-day storage period may be due to starch hydrolysis, which produces mono and disaccharides (Ryall and Pentzer, 1982). Reducing sugar contents in fruits have been found to increase during the maturation process in storage. (Fuchs et al., 1980). The lowered sugar content in fruits caused by polythene wrapping was attributed to a slower metabolic rate.

\section{Total sugars $(\%)$}

The total sugar content of mango fruits treated with various treatments followed a similar pattern to the TSS content (Figure 3). The early increase in total sugars of fruits in different packaging could be attributed to water loss from the fruits and sugar conversion from polysaccharides and pectic compounds. The hydrolysis of starch, which produces mono and disaccharides, could explain the increase in total sugars at storage intervals of up to 12 days (Ryall and Pentzer, 1982).

\section{Titratable acidity (\%)}

For all of the treatments, the overall titratable acidity of the fruits decreased during storage. 


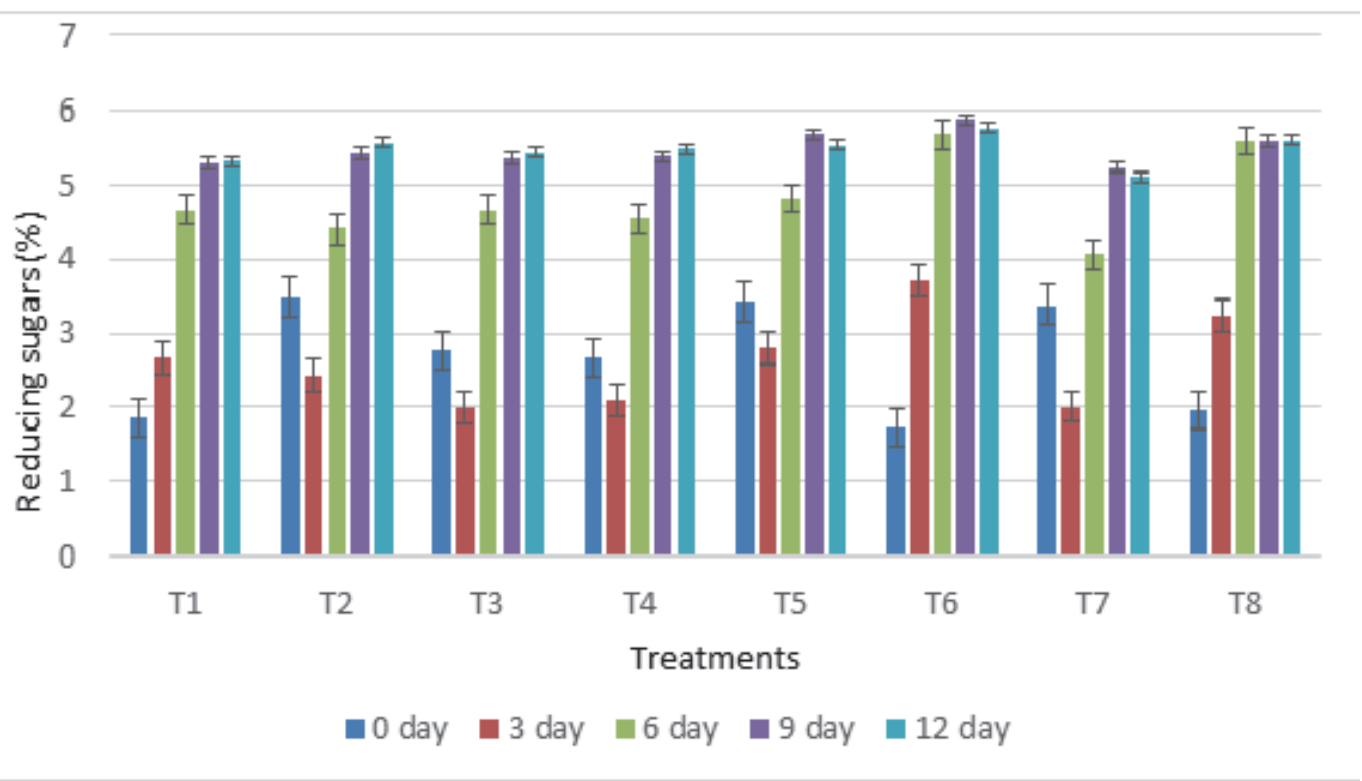

Figure 2. Effect of wrapping materials and storage on Reducing sugars (\%)

Maini et al., (1984) also reported such a drop in acidity as a result of fruit storage.

The decrease in acidity may be explained by the use of organic acids as a respiratory substrate during storage, and hence the conversion of acids into sugars. However, the preservation of acidity in polythene-wrapped fruits during storage may be attributed to a decline in organic acid hydrolysis and subsequent accumulation of organic acids that were oxidized at lower rate due to reduced respiration The results are in line with Venkatesha and Reddy's findings (1994), (Figure 4)

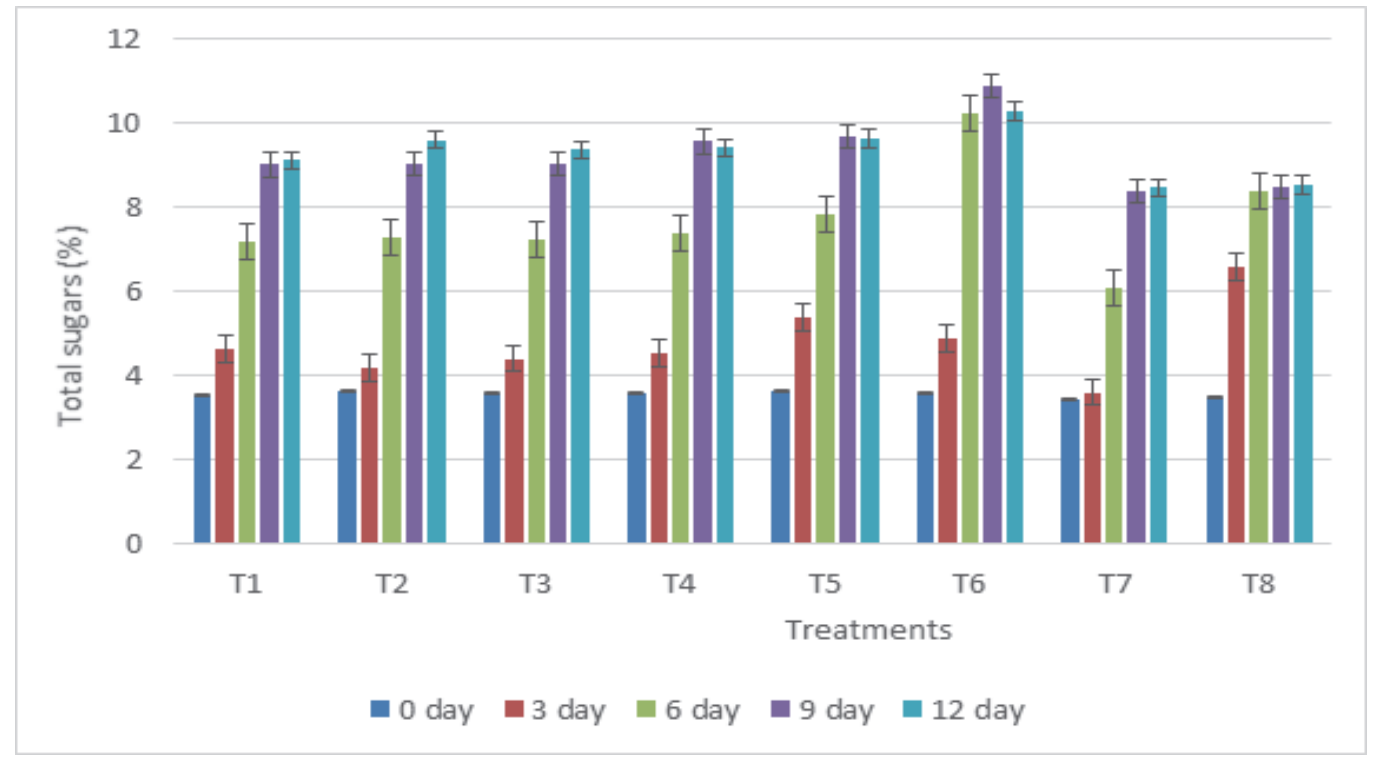

Figure 3. Effect of wrapping materials and storage on Total sugars (\%) 


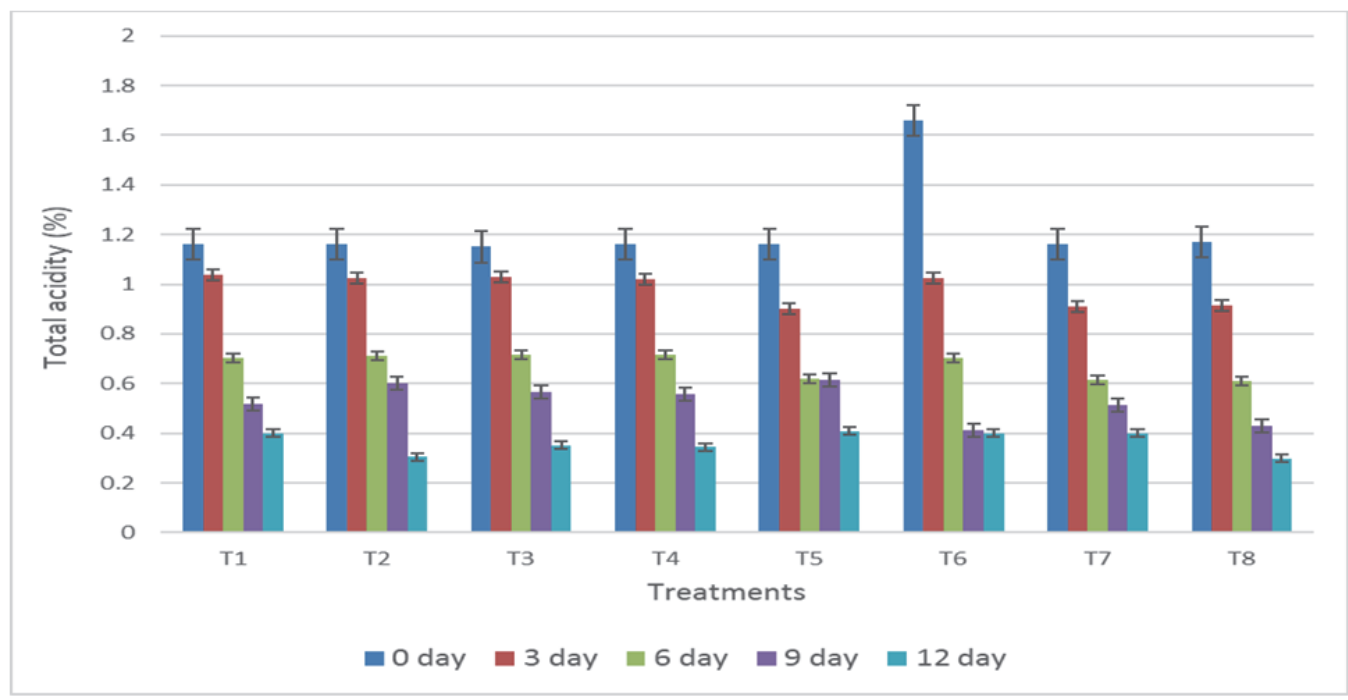

Figure 4. Effect of wrapping materials and storage on Total acidity (\%)

\section{Sensory Evaluation}

In the mango fruits packed in, the CFB box in the cold store got the highest sensory test score of all the treatments. This is mostly due to the fact that the treatment led to decrease physiological weight loss and spoilage loss, as well as fruit firmness, color change, and nutrient loss during storage. Sharma and Singh (2010) agree with this finding (Table 2). The least quality sensory was reported in 'Khirsapat' mango $\mathrm{T}_{1}$ (Low-density polyethylene + No perforation), which can be attributed to the low fruit quality and strong aldehydic flavor of the fruit, which makes it low in quality for consumption (Lakshmana et al., 2013).

Table 2. Sensory score for 'Khirsapat' Mango

\begin{tabular}{|c|c|c|c|c|c|c|c|c|c|}
\hline \multirow{2}{*}{ Treatments } & \multicolumn{3}{|c|}{ Colour } & \multicolumn{3}{c|}{ Flavour } & \multicolumn{3}{c|}{ Overall } \\
\cline { 2 - 10 } & $6^{\text {th }}$ day & $9^{\text {th }}$ day & $12^{\text {th }}$ day & $6^{\text {th }}$ day & $9^{\text {th }}$ day & $12^{\text {th }}$ day & $6^{\text {th }}$ day & $9^{\text {th }}$ day & $12^{\text {th }}$ day \\
\hline $\mathrm{T}_{1}$ & 5.8 & 6.6 & 1.0 & 4.0 & 6.6 & 1.5 & 9.8 & 13.4 & 2.2 \\
\hline $\mathrm{T}_{2}$ & 6.4 & 6.7 & 7.6 & 6.3 & 7.2 & 8.3 & 12.4 & 13.8 & 16 \\
\hline $\mathrm{T}_{3}$ & 6.1 & 6.7 & 7.8 & 5.1 & 6.9 & 8.3 & 11.1 & 13.6 & 14.5 \\
\hline $\mathrm{T}_{4}$ & 6.3 & 6.6 & 8.0 & 5.2 & 7.1 & 8.1 & 11.5 & 13.7 & 14.4 \\
\hline $\mathrm{T}_{5}$ & 6.9 & 7.5 & 8.6 & 5.3 & 7.4 & 8.5 & 12.2 & 14.8 & 17.2 \\
\hline $\mathrm{T}_{6}$ & 7.1 & 7.8 & 8.5 & 4.5 & 7.5 & 7.9 & 11.5 & 15.2 & 16.2 \\
\hline $\mathrm{T}_{7}$ & 6.8 & 7.1 & 7.8 & 6.1 & 6.8 & 7.8 & 12.9 & 13.9 & 15.6 \\
\hline $\mathrm{T}_{8}$ & 8.2 & 1.1 & 1.2 & 8.4 & 1.0 & 1.0 & 16.6 & 2.1 & 2.2 \\
\hline SEm ( $)$ & 0.67 & 0.41 & 0.71 & 0.73 & 0.51 & 0.42 & 1.4 & 0.92 & 1.13 \\
\hline C.D 5\% & 0.002 & 0.002 & 0.003 & 0.001 & 0.001 & 0.003 & 0.003 & 0.003 & 0.006 \\
\hline
\end{tabular}

$T_{1}=$ Low-density polyethylene $(L D P E)+$ No perforation, $T_{2}=L D P E+5 \%$ perforation, $T_{3}=L D P E+$ Blotting paper inside, $T_{4}=L D P E+5 \%$ perforation + Blotting paper inside, $T_{5}=$ Corrugated Fiber Board (CFB) Box (5\% ventilation), $T_{6}=\operatorname{LDPE}\left(5 \%\right.$ perforation) + CFB Box (5\% ventilation), $T_{7}=$ Plastic crate, $T_{8}=$ Control (without any wrapping) 


\section{CONCLUSIONS}

Based on the findings of the research, it can be concluded that 'Khirsapat' mango can be packed in $\mathrm{T}_{6}$ (LDPE $5 \%$ perforation + CFB Box $5 \%$ ventilation) at a temperature of $12^{\circ} \mathrm{C}$ for up to 12 days with minimal biochemical quality loss and satisfactory sensory quality. As a result, the findings can be used to store mango fruits after they have been collected.

\section{ACKNOWLEDGEMENTS}

This research has been financed by Ministry of Science \& Technology, Government of the People`s Republic of Bangladesh under Research \& Development project in Food \& Agriculture.

\section{REFERENCES}

1. A. O. A. C. (1990). Official methods of analysis. Association of Official Analytical Chemists, 881-882.

2. BBS (2019). Statistical Year Book of Bangladesh. Statistics Division, Agriculture Wing, Ministry of Planning, Government of the People's Republic of Bangladesh. Dhaka, 150.

3. Cua, A. U. (1989). Ethylene biosynthesis in" carabao" mango fruit (Mangifera indica L.) during maturation and ripening.

4. Fuchs, Y., Pesis, E., and Zauberman, G. (1980). Changes in amylase activity, starch and sugars contents in mango fruit pulp. Scientia Horticulturae, 13(2), 155-160.

5. Johnson, P. R., and Ecker, J. R. (1998). The ethylene gas signal transduction pathway: a molecular perspective. Annual review of genetics, 32(1), 227-254.

6. Maini, S. B., Diwan, B., Lal, B. B., and Anand, J. C. (1984). Comparative performance of packing apples in trays and conventional pack during transit. Journal of food science and technology (Mysore), 21(6), 409-410.

7. Malik, A. U., Amin, M., Jabbar, A., and Saleem, B. A. (2008). Packaging material and ripening methods affect mango fruit quality. Int. J. Agri. Biol, 10, 35-41.

8. Pongener, A., Mahajan, B. V. C., and Singh, H. (2011). Effect of different packaging films on storage life and quality of peach fruits under cold storage conditions. Indian Journal of Horticulture, 68(2), 240-245.

9. Ranganna, S. (1991). Handbook of analysis of quality control for fruit and vegetable pProducts. 2nd ed. Tata McGrawHill Pub. Co. Ltd. New Delhi, 27(3).

10. Ryall, A. L., and Pentzer, W. T. (1982). Handling, transportation and storage of fruits and vegetables. Volume 2. Fruits and tree nuts. AVI Publishing Co., Inc.

11. Siddiqui, M. W., and Dhua, R. S. (2009). Standardization of ethrel treatment for inducing ripening of mango var. 'Himsagar'. In Proceedings of International Conference on Horticulture (ICH-2009), Bangalore, (9-12).

12. Singh, S. K., Singh, S. K., and Sharma, R. R. (2010). Pruning alters fruit quality of mango cultivars (Mangifera indica L.) under high density planting. Journal of Tropical Agriculture, 48(2), 55-57.

13. Srivastava, R. P. (Ed.). (1998). Mango cultivation. International Book Distributing Company.

14. Venkatesha, M., and Venkatesh Reddy, T. (1994). Use of Polyethylene Bags to extend the Shelf life of Guava (Psidium guajava L.) Fruits. Indian Food Packer, 48, 5-5.

15. Wills, R. B. H., Bambridge, P. A., and Scott, K. J. (1980). Use of flesh firmness and other objective tests to determine consumer acceptability of delicious apples. Australian Journal of Experimental Agriculture, 20(103), 252-256. 